\title{
Grasping the World: Object-Affordance Effect in Schizophrenia
}

\author{
Jessica Sevos, ${ }^{1,2}$ Anne Grosselin,, ${ }^{1,2}$ Jacques Pellet, ${ }^{1,2}$ \\ Catherine Massoubre, ${ }^{1,2}$ and Denis Brouillet ${ }^{2}$ \\ ${ }^{1}$ Department of Psychiatry, University Hospital of Saint-Etienne, Pavillon 52A, 25 Boulevard Pasteur, \\ 42055 Saint-Etienne Cedex 2, France \\ ${ }^{2}$ Epsylon Laboratory, EA4556, Dynamics of Human Abilities and Health Behaviours, University of Montpellier III, \\ Rue du Pr. Henri Serre, 34000 Montpellier, France
}

Correspondence should be addressed to Jessica Sevos; j.sevos@hotmail.fr

Received 10 July 2013; Accepted 4 November 2013

Academic Editor: Anil K. Malhotra

Copyright (C) 2013 Jessica Sevos et al. This is an open access article distributed under the Creative Commons Attribution License, which permits unrestricted use, distribution, and reproduction in any medium, provided the original work is properly cited.

For schizophrenic patients, the world can appear as deprived of practical meaning, which normally emerges from sensory-motor experiences. However, no research has yet studied the integration between perception and action in this population. In this study, we hypothesize that patients, after having controlled the integrity of their visuospatial integration, would nevertheless present deficit in sensory-motor simulation. In this view, we compare patients to control subjects using two stimulus-response compatibility (SRC) tasks. Experiment 1 is performed to ensure that visuo-spatial integration is not impaired (Simon Effect). Experiment 2 replicates a study from Tucker and Ellis (1998) to explore the existence of sensory-motor compatibility between stimulus and response (Object Affordance). In control subjects, the SRC effect appears in both experiments. In schizophrenic patients, it appears only when stimuli and responses share the same spatial localization. This loss of automatic sensory-motor simulation could emerge from a lack of relation between the object and the subject's environment.

\section{Introduction}

For the embodied theories of cognition, it is largely accepted that cognitive processes in healthy subjects are deeply rooted in the sensory-motor systems. The cognitive functioning is carried out dynamically, throughout a context, a situation, a task, and a body status [1]. More particularly, perception and action are inseparable; indeed, perception has to be understood as an action guided towards its aim.

This embodied view of mind is in accordance with Merleau-Ponty's [2] phenomenology of perception in which the organism and environment are coupled. For him, the body's actions are the conditions for entering into a cognitive relationship with the world. In relation to both motor and perceptual abilities of the subject, the objects of the world are perceived as "practicable" objects.

In the embodied theories of cognition, the concept of affordance, originally introduced by Gibson [3] in 1977, has a key role. Indeed, affordances depend on the context, perceptual characteristics of objects and on the body; objects, and environment are seen in terms of opportunity of actions [4].
The visual representation of an object comes from the binding between its visual properties and related action potentialities via sensory-motor simulations. Both behavioral [5-9] and brain imaging studies [10-12] indicate that the representation of perceived objects incorporates motor information. This action-perception binding thus allows all living being to automatically perceive an object as a support for its action.

To explore this idea, Tucker and Ellis [13] used a stimulus response compatibility (SRC) paradigm. Tasks using this paradigm highlight that performances not only depend on the stimuli or response modalities but also on the way these elements combine themselves together. According to this paradigm, when the stimulus and the response share the same properties, response times are shorter than when they do not: this is the "SRC effect" [14]. In their study, Tucker and Ellis [13] focused on the action potentiation effect when perceiving graspable objects. They asked participants to answer, with their right or left hand, to the vertical orientation (upright or inverted) of a graspable object presented in the middle of the screen. They found that responses were faster when there is a compatibility between the graspable part of the 
object and the response hand (right-hand response with the handle oriented to the right hand side or left-hand response with the handle oriented to the left side) than when there is incompatibility. In this experimental context, Tucker and Ellis [13] postulated that the intrinsic properties of the objects emerge from perception without action instructions: the "object-based affordance effect" [10]. In other words, seen objects automatically potentiate components of the actions they afford.

Another well-known effect can be found using an SRC paradigm, based here on the congruency between the spatial localization of the stimulus and the motor response: the "Simon effect" [15]. Due to a visuo-spatial integration, response times are faster when the stimulus is presented on the right hand side of the screen and the response is given by the right hand (the same congruency is found for the left hand side/left hand).

Certain authors postulate that the object-based affordance effect, shown by Tucker and Ellis [13], could be due to a spatial Simon effect. For them, the visual asymmetry of stimuli would tend to capture visual attention and create a visuo-spatial compatibility between the spatial localization of the stimulus and motor response side $[16,17]$. Conversely, for Symes et al. [18] or Buccino et al. [19], object-based affordance could clearly be distinguished from the spatial Simon effect. For them, automatic responses would be guided by the intrinsic properties of the objects and not by their spatial localization [10].

In psychopathology of schizophrenia, symptoms such as derealization (external world feels strange or transformed) and depersonalization (feeling of being strange or having one's own body transformed) are encountered [20, 21], even if new treatments improve frequently these symptoms. More recently, authors that build on the work of phenomenological philosophers such as Heiddeger [22], describe schizophrenia's main disorder as a fundamental disorder of self-embodiment, relating to a loss of a sense of familiarity with the external world [23-25]. Even if patients presenting with schizophrenia are able to identify objects in their environment, they are frequently not able to use them without adaptive strategies. These considerations offer a new reading of impaired subjective experiences or of disturbed social interactions [26, 27]. Usually, the body allows the subject to be adapted to the world and to others, throughout an embodied common sense and certain "know-how" [28]. However, patients may sometimes behave as if they have a body without a spirit or a spirit without a body; this may question the embodiment of the self, of the object relation, or social relationships in this population [24].

According to Sass and Parnas [29], things usually tacit for healthy subjects would become explicit for patients. Sensorymotor processes, normally automatic, would become available for conscious introspection in this population, due to a fragmentation of automatic perceptual and motor schemes [25]. This could lead to a loss of the feeling of inhabiting their own perception, actions, bodily sensations, and also to a disturbance of basic self-awareness in schizophrenia $[25,30]$. Thus, it would become difficult for patients to "organize the experiential world in accordance with needs and wishes, thereby giving objects their affordance" [30]. For patients, the world can appear as deprived of practical meaning, which normally emerges from sensory-motor experiences. However, can a phenomenon such as affordance still emerge if subject and environment are not interlinked anymore?

In this population of patients, no research has yet specifically studied the automatic integration between perception and action, which constitute the foundation of an embodied cognition. However, on an experimental level, a few cognitive studies take an interest in the general question of perception and action in schizophrenia. Enticott et al. [31] showed a decrease of motor-evoked potentials in schizophrenic patients, when seeing actions compared to healthy subjects. Franck et al. [32] demonstrated that it is more difficult for patients than for control subjects to recognize their movements as their own. Delerue and Boucart [33] are the only authors suggesting impairment for the detection of object-affordances in schizophrenic patients. Using an eyetracking task, they asked subjects to either name the objects or the actions inferred by the objects presented. Results showed that healthy subjects explored the whole object in the actionnaming task and only the part needed for identification in the object-naming task, whereas patients used the same visual exploration patterns for both tasks.

Nevertheless, the visuo-spatial compatibility is not taken into account in these studies. To our knowledge, the only study having used the Simon paradigm in schizophrenia showed a visuo-spatial compatibility specifically when the stimuli were presented in the left hemifield [34].

In this paper, we propose to use the SRC paradigm, classically used in an embodied perspective of cognition, in order to explore the integration between perception and action in this pathology. Such a study implies to control the integrity of visuo-spatial integration and, in order to achieve this, we use a Simon task (Experiment 1). In Experiment 2, we explore the hypothesis that schizophrenic patients could have a deficit in sensory-motor simulation during perception of graspable objects, in contrast to healthy subjects. In schizophrenia, the sensory-motor simulation impairments could emerge from a lack of connection between the object and the subject's environment without impairment in visuospatial integration.

\section{Experiment 1}

2.1. Participants. Seventeen schizophrenic patients, recruited from the University Hospital of Saint-Etienne, participated in the study. All were outpatients living in their own accommodation with various psychosocial or professional activities. The inclusion criteria were a DSM-IV diagnosis of schizophrenia [35]; there was no change in antipsychotic medication and clinical status within four weeks prior to the study. All patients were assessed by the same psychiatrist with the positive and negative syndrome scale (PANSS) [36], which showed the predominance of a positive syndrome on 9 patients and of a negative syndrome on 8 patients.

Seventeen healthy control subjects recruited via advertisement in the local newspaper were matched to the schizophrenic subjects on age, years of education, and score on 
TABle 1: Age, years of education, and Edinburgh scores (SD) comparison between patients and control subjects for Experiment 1.

\begin{tabular}{lccc}
\hline & Controls $(N=17)$ & Patients $(N=17)$ & $t$-test; $P$ value \\
\hline Age (years) & $33.9(8.2)$ & $36.2(6.4)$ & $t=.902, P=.204$ \\
Education (years) & $12.8(2.3)$ & $12.2(2)$ & $t=-.723, P=.963$ \\
Edinburgh score $(/ 20)$ & $18.9(145)$ & $18.1(1.7)$ & $t=1.292, P=.215$ \\
\hline
\end{tabular}

TABLE 2: Error rates (SD) comparison between groups in Experiment 1.

\begin{tabular}{|c|c|c|c|c|}
\hline & & Patients & Controls & $t$-test; $P$ value \\
\hline \multirow{2}{*}{ Compatibility } & Right hand & $0.2(0.5)$ & $0.6(0.7)$ & $t=-1.692, P=.110$ \\
\hline & Left hand & $0.2(0.6)$ & $0.6(1)$ & $t=-1.191, P=.251$ \\
\hline \multirow{2}{*}{ Incompatibility } & Right hand & $0.6(0.9)$ & $0.2(0.8)$ & $t=1.383, P=.186$ \\
\hline & Left hand & $0.2(0.6)$ & $0.4(0.6)$ & $t=-.523, P=.608$ \\
\hline
\end{tabular}

a modified Edinburgh Handedness Inventory [37] (see Table 1 for mean group scores and statistical comparisons).

The noninclusion criteria for all participants were (1) a diagnosis of neurological brain disorder or head trauma with loss of consciousness, (2) a mental retardation, (3) history of substance abuse over the last 6 months, and (4) an Edinburgh score inferior to 14 .

The study was approved by the local Ethics Committee from Saint-Etienne, and an informed written consent was obtained from all participants.

2.2. Apparatus and Materials. In this task, we used the computer-based attention battery TAP [38]. In this task, arrows, pointing left or right, appear either on the left or righthand side of a fixation point.

2.3. Design and Procedure. Each participant carried out a block of 60 trials. Subjects had to press the response key as fast and accurately as possible with their right or left index, according to the direction of the arrow, without taking into consideration its side of appearance. White arrows were presented on a black screen, either pointed to the same side of its appearance (compatibility) or to the opposite side (incompatibility). The response keys were situated $15 \mathrm{~cm}$ apart and $20 \mathrm{~cm}$ in front of the screen. The order of trials was randomized between subjects.

Before the beginning of the experiment, subjects were seated with their head $50 \mathrm{~cm}$ in front of the screen. Each experimental trial started with a fixation point of $1500 \mathrm{~ms}$, immediately followed by an arrow presented on a black screen. The stimulus was flashed on the screen every $3000 \mathrm{~ms}$. If no answer was given before $2000 \mathrm{~ms}$ ended, the message "no response" appeared for an extra $2000 \mathrm{~ms}$. Each participant received 7 practice trials.

2.4. Results. For all conditions, participants responded during the first $2000 \mathrm{~ms}$. No differences on mean error rates were found between patients and control subjects (see Table 2).

The mean response times (RT) and SD were calculated for each subject; RT above 2 SD of their own individual mean were eliminated (under 5\%).
An analysis of variance (ANOVA) was conducted on the participants' data with Group (controls or patients) as between subject factor, and Response (left or right hand) and Field (left or right hemifield) as within subject factor. Patients (461 ms) were not significantly slower than controls (445 ms) $\left(F_{(1,32)}=0.570, \eta^{2}=0.01, P=.461\right)$. There was a main effect of Response $\left(F_{(1,32)}=9.169, \eta^{2}=0.22, P=.008\right)$, but the Response $\times$ Group interaction was not significant $\left(F_{(1,32)}=\right.$ 1.966, $\left.\eta^{2}=0.05, P=.180\right)$. The main effect of Field was significant $\left(F_{(1,32)}=4.753, \eta^{2}=0.12, P=.045\right)$ with faster response times when the arrows were presented in the right hemifield (446 ms) compared to the left (459 ms). The Field $\times$ Group interaction was not significant $\left(F_{(1,32)}<1\right)$. The 2-way interaction between Field and Response (which measures the Simon effect) was found $\left(F_{(1,32)}=31.994, \eta^{2}=0.49\right.$, $P=.001)$. Right-hand responses were faster when the object appeared in the right hemifield $(423 \mathrm{~ms})$ rather than in the left $\left(470 \mathrm{~ms} ; t_{(16)}=-5.324, \eta^{2}=0.63, P=.001\right)$. Similarly, lefthand responses were faster when the object appeared in the left hemifield (449 ms) rather than in the right $\left(470 \mathrm{~ms} ; t_{(16)}=\right.$ $\left.2.546, \eta^{2}=0.28, P=.016\right)$. In addition, this effect was not significantly modified by group $\left(F_{(1,32)}=1.013, \eta^{2}=0.03\right.$, $P=.329$ ) (see Figure 1).

In this experiment, control subjects and patients showed the same pattern of responses; their RTs are faster when there was compatibility between the spatial localization of the stimulus and the motor response. After having controlled the integrity of visuo-spatial integration in schizophrenic group, we explore, in Experiment 2, if they present impairment in sensory-motor simulation.

\section{Experiment 2}

3.1. Participants. All of the patients and control subjects from the first experiment also carried out this second one; 3 new patients and 3 new control subjects were contacted in order to expand the sample size, which helps to boost statistical reliability. The 2 groups were still matched in ages, years of education scores, and handedness (see Table 3 for mean group scores and statistical comparisons). 


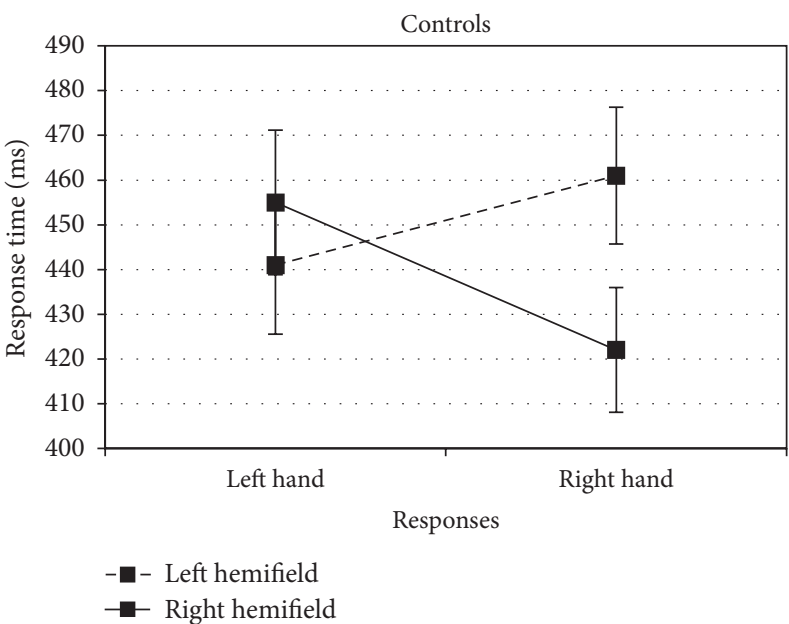

(a)

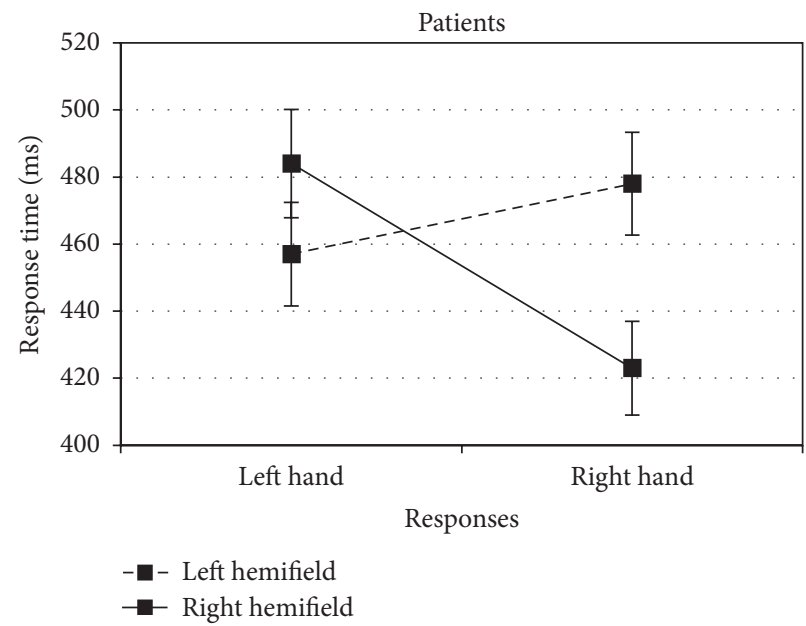

(b)

FiguRE 1: Mean response times for Experiment 1 as a function of groups (controls or patients), hemifield (left or right), and responses (left or right hand).

TABLE 3: Age, years of education, and Edinburgh scores (SD) comparison between patients and control subjects for Experiment 2.

\begin{tabular}{lccc}
\hline & Controls $(N=20)$ & Patients $(N=20)$ & $t$-test; $P$ value \\
\hline Age (years) & $34.1(8.4)$ & $36.2(5.9)$ & $t=.935, P=.356$ \\
Education (years) & $12.8(2.1)$ & $11.9(2.8)$ & $t=-1.228, P=.227$ \\
Edinburgh score $(/ 20)$ & $18.3(1.7)$ & $18.7(1.5)$ & $t=.779, P=.441$ \\
\hline
\end{tabular}

New patients were assessed by the same psychiatrist with the positive and negative syndrome scale (PANSS) [36]. The group as a whole showed the predominance of a positive syndrome on 11 patients and of a negative syndrome on 9 patients.

3.2. Apparatus and Materials. Black and white photos of 22 objects were used (see Appendix). All of the objects were graspable by one hand and were photographed in 2 horizontal orientations (compatible either with a right or left hand grasp) and 2 vertical orientations (upright or inverted) (see Figure 2). Consequently, 88 pictures were presented in the middle of a computer screen. On the screen, all average size was $512 \times 384$ pixels, maintaining the proportions of each object at a distance of $50 \mathrm{~cm}$.

3.3. Design and Procedure. Each participant carried out 2 blocks of 88 trials with a 3-minute pause between each block. These blocks differed in terms of response mapping (right hand-upright/left hand-inverted and left hand-upright/right hand-inverted) and were counterbalanced between subjects. They had to press the response key as fast and accurately as possible, with their right or left index, according to the vertical orientation of the objects (upright or inverted). Subjects kept their right finger on a right response key and their left finger on a left response key during the whole experiment. Depending on the situation, the response hand could be on the same side as the graspable part of the object (compatibility) or on the opposite side (incompatibility).

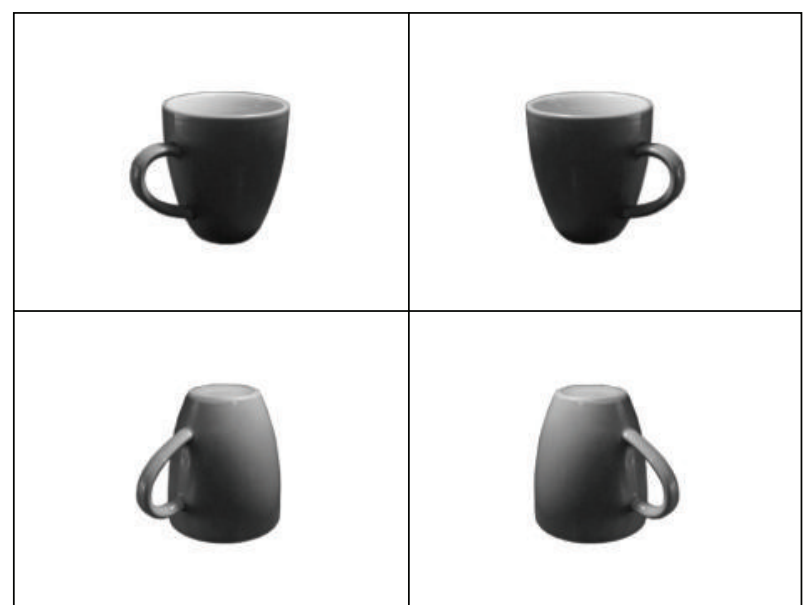

FIgURE 2: Examples of the stimuli used in Experiment 2: left orientation, upright; right orientation, upright; left orientation, inverted; right orientation, inverted.

On a standard AZERTY keyboard, the response keys were situated $15 \mathrm{~cm}$ apart and $20 \mathrm{~cm}$ in front of the screen. The order of trials was randomized between subjects.

Before the beginning of the experiment, subjects were seated with their head $50 \mathrm{~cm}$ in front of the screen. Every photo was shown to the participants, in order to be sure that they recognized the object, in upright or inverted orientation. Each experimental trial started with a 1500 ms fixation point, 
TABLE 4: Error rates (SD) comparison between groups in Experiment 2.

\begin{tabular}{|c|c|c|c|c|}
\hline & & Patients & Controls & $t$-test; $P$ value \\
\hline \multirow{2}{*}{ Compatibility } & Right hand & $4.4(3.1)$ & $3.8(2.3)$ & $t=.765, P=.449$ \\
\hline & Left hand & $4.2(3.5)$ & $2.6(2.5)$ & $t=1.704, P=.096$ \\
\hline \multirow{2}{*}{ Incompatibility } & Right hand & $4.5(3.7)$ & $4.3(3.2)$ & $t=.183, P=.856$ \\
\hline & Left hand & $4.1(2.9)$ & $4.3(2.5)$ & $t=-.288, P=.775$ \\
\hline
\end{tabular}

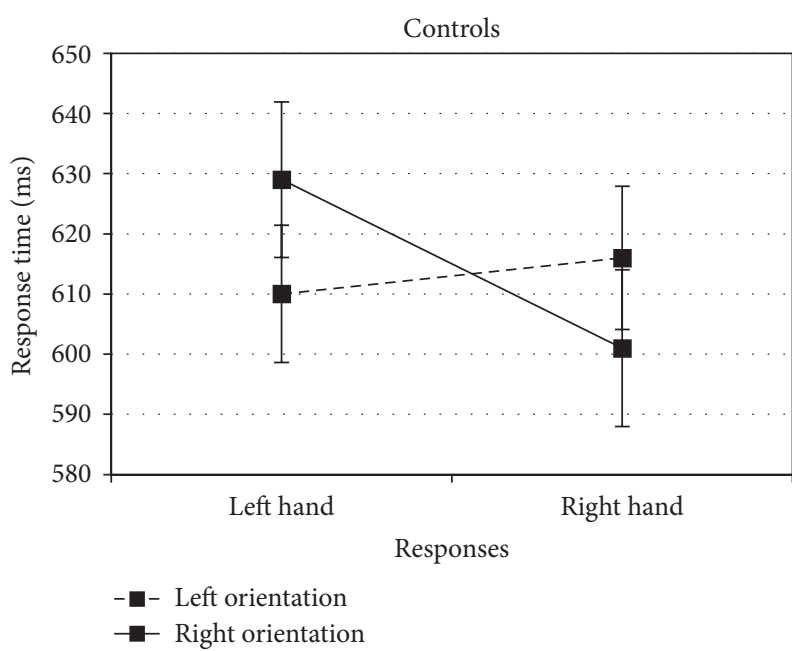

(a)

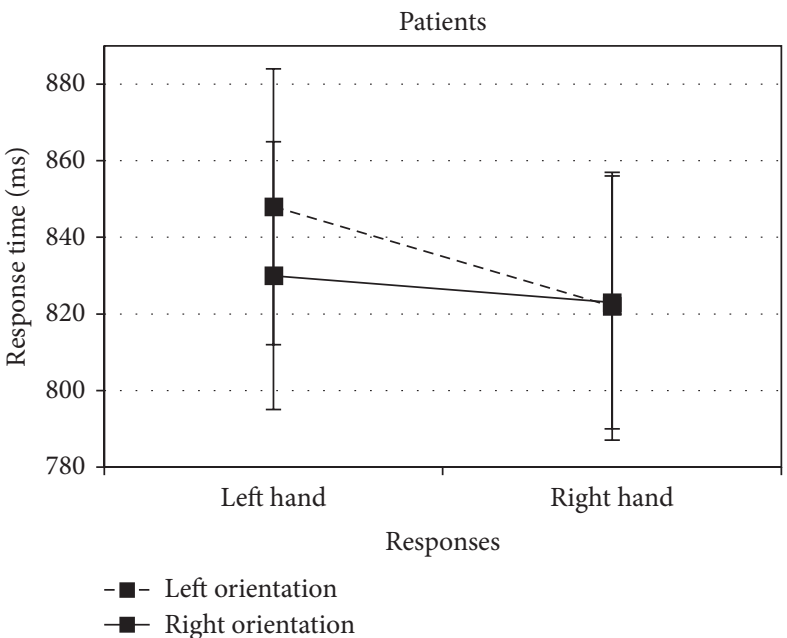

(b)

Figure 3: Mean response times for Experiment 2 as a function of groups (controls or patients), orientations (left or right), and responses (left or right hand).

immediately followed by an object presented on a white screen. The stimulus stayed on the screen until an answer was given or during $3000 \mathrm{~ms}$ if not. Participants were given feedback on errors (short tone). Each participant received 16 practice trials (with other photos of objects) before each block.

3.4. Results. For all conditions, participants responded during this given time of $3000 \mathrm{~ms}$. No differences on mean error rates were found between patients and control subjects (see Table 4).

The mean response times (RT) and SD were calculated for each subject; RT above 2 SD of their own individual mean were eliminated (under 5\%).

An analysis of variance (ANOVA) was conducted on the participants' data with Group (controls or patients) as between subject factor, and Response (left or right hand) and object Orientation (left or right) as within subject factors.

Globally, patients showed increased RT compared with controls as reflected by a significant main effect of group $\left(F_{(1,38)}=31.77, \eta^{2}=0.45, P=.001\right)$. We also found a main effect of Response $\left(F_{(1,38)}=7.347, \eta^{2}=0.16, P=.014\right)$ with longer RT when subjects gave left hand responses $(729 \mathrm{~ms})$ in comparison to right hand responses $(716 \mathrm{~ms})$. However, the Response $\times$ Group interaction was not significant $\left(F_{(1,38)}<\right.$ $1)$, reflecting similar costs produced by left hand responses across groups. The main effect of object Orientation was not significant $\left(F_{(1,38)}=.733, \eta^{2}=0.01, P=.403\right)$ in the same way as the Orientation $\times$ Group interaction $\left(F_{(1,38)}=.898\right.$, $\left.\eta^{2}=0.02, P=.355\right)$. Whilst the Response $\times$ Orientation interaction (which measures the compatibility effect) was not significant $\left(F_{(1,38)}=1.520, \eta^{2}=0.03, P=.233\right)$, the most interesting result was the three-way Group $\times$ Response $\times$ Orientation interaction $\left(F_{(1,38)}=11.956, \eta^{2}=0.23, P=.003\right)$ (see Figure 3$)$. In the control group, right-hand responses were faster when the orientation of the object was also to the right rather than to the left $\left(t_{(19)}=-2.567, \eta^{2}=0.25\right.$, $P=.019)$. Similarly, left-hand responses were faster when the orientation of the object was also to the left rather than to the right $\left(t_{(19)}=3.151, \eta^{2}=0.34, P=.005\right)$. The Response $\times$ Orientation two-way interaction was significant $\left(F_{(1,19)}=\right.$ $\left.25.962, \eta^{2}=0.57, P=.001\right)$. In the patient group, there was no such significant difference for right-handed responses to objects oriented to the right or to the left $\left(t_{(19)}<1\right)$. Left handed responses to objects oriented to the right were actually faster than the responses to objects oriented to the left $\left(t_{(19)}=-1.845, \eta^{2}=0.15, P=.081\right)$. The Response $\times$ Orientation two-way interaction was not significant $\left(F_{(1,19)}=\right.$ 2.114, $\eta^{2}=0.09, P=.162$ ).

To control a possible tiredness effect due to task in the patient group, we compared RT and errors between the first 44 trials of the first block and the last 44 trials of the second block. There was no difference in RT between the first 44 trials $(843 \mathrm{~ms})$ and the last 44 trials $(842 \mathrm{~ms})\left(t_{(19)}<1\right)$. This 
pattern was also found for the error rates (resp. 4,8\% and 5\%; $\left.t_{(19)}<1\right)$.

In this second experiment, we found the same results as Tucker and Ellis [13] on control subjects' RT. Their responses were faster when there was compatibility between the orientation of the prehensile part of common graspable objects and the response hand. However, this object-based affordance effect did not emerge in the schizophrenic group.

\section{General Discussion}

The aim of these tasks was to investigate if schizophrenic patients have a deficit in sensory-motor simulation without impairment in visuo-spatial integration. In Experiment 1, we demonstrated that the compatibility between the spatial localization of a stimulus and of the motor response leaded to faster response times, even for schizophrenic patients. Experiment 2 replicated the results of Tucker and Ellis [13] on control subjects. Responses were faster when there was compatibility between the orientation of common graspable objects and the response hand. However, this object-based affordance effect was not found in the schizophrenic group.

These results seem particularly interesting; for schizophrenic patients, the stimulus response compatibility effect does not appear for every condition (Simon-task and affordance-task). Indeed, our results show that, in this population, the SRC effect appears only when stimulus and response share a visuo-spatial localization. This Simon effect is already partly found in the study of Gastaldo et al. [34] which focuses only on patients with negative symptoms. They show a spatial compatibility only when the stimuli are presented in the left hemifield. Let us underline that this study focuses on abnormalities of visual attention, frequently reported in patients [39], rather than on the Simon effect. Our results demonstrate that, for both positive and negative symptom patients, the Simon effect appears in both hemifields. Moreover, there is no group difference in RT measures, as already found by Behrwind et al. [40] in a visuo-spatial version of SRC tasks. In the schizophrenic group, the visuo-spatial integration seems to be automatic, in the same way as in control subjects.

However, even for patients with a low level of symptom severity, our results do not bring to light the object-affordance effect. During the task replicating Tucker and Ellis' experiment [13], our results show an increase of patients' RT in comparison to those of the control group. This increase is not due to a possible tiredness effect. However, it could reflect an absence of automatic simulation which normally appears when stimulus and response share sensory-motor characteristics. In the patient group, it would seem that the automatic binding between perception and action does not take place. Thus, the increased RT could reflect the implementation of controlled processes more costly in attentional resources.

Our 2 experiments, using the SRC paradigm, seem to distinguish the spatial Simon effect from an object-based affordance effect, as already found by Symes et al. [18] and Buccino et al. [19]. However, for other authors [16, 17], the perceptive asymmetry of manipulable objects would virtually make the graspable part seem closer to the hand; this perceptive salience would attract visual attention. Buccino et al. [19] use a cup with a broken handle, which has the same visual asymmetry as an undamaged cup. They show that this broken cup does not trigger off the premotor activity linked to the perception of an undamaged cup. In this case, a broken cup would not represent a typical graspable object, underlying the importance of the pragmatic role of an object. If object-affordance effect only emerges from a visual asymmetry, patients in our study should have similar results to control subjects on the Tucker and Ellis task [13]. The contrast between the patterns of results of the two experiments in schizophrenic patients, leads us to think that the implementation of sensory-motor simulation is a different effect from visual saliency.

Consequently, if patients present sensory-motor integration impairment, the relationship between the object's features and the action to carry out cannot automatically be "built". Alternative explanations of lack of interest or deficit in attention could not account for the reduced affordanceeffect in patients with schizophrenia because they do not make more errors than control subjects. However, making the action more specific to the patient's needs and wishes or reinforcing the purpose of the action could help create this automatic link between perception and action.

To conclude, the results of our study on object-affordance seem to us, even if more confirmative studies are needed, a promising way to enlarge knowledge on cognitive disturbances of embodiment in schizophrenia. They could also highlight a cognitive basis of phenomenon like depersonalization and derealization, that is, perturbations of links between patients and their environment. These considerations could join the following Stanghellini's quote [41]: "if my body-based involvement in the world is switched off, my grasp onto the world will fade away too".

\section{Appendix}

\section{Objects Used in Experiment 1}

Watering plant
Handled dustpan
Bottle of detergent
Bottle of detergent
Kettle
Coffee pot
Coffee pot
Saucepan
Saucepan
Knife
Knife
Iron
Whisk
Mug
Mug
Sieve
Sieve
Watering can
Frying pan
Frying pan


Small jug

Remote control.

\section{Conflict of Interests}

There is no conflict of interests in relation to the subject of this study.

\section{Acknowledgments}

The authors thank the patients and the control subjects for taking part in the study. They also thank Miss ChesnoyServanin, native speaker, who proofread this paper. This study was supported by the University Hospital of SaintEtienne, France.

\section{References}

[1] F. Varela, E. Thomson, and E. Rosch, L'Inscription Corporelle de l'Esprit, Seuil, Paris, France, 1993.

[2] M. Merleau-Ponty, Phénoménologie de la Perception, Gallimard, Paris, France, 1945.

[3] J. J. Gibson, "The theory of affordances," in Perceiving, Acting, And Knowing: Toward an Ecological Psychology, R. Shaw and J. Bransford, Eds., Lawrence Erlbaum, New Jersey, NJ, USA, 1977.

[4] D. Caligiore, A. M. Borghi, D. Parisi, R. Ellis, A. Cangelosi, and G. Baldassarre, "How affordances associated with a distractor object affect compatibility effects: a study with the computational model TRoPICALS," Psychological Research, vol. 77, pp. 7-19, 2013.

[5] A. M. Borghi and D. Pecher, "Introduction to the special topic embodied and grounded cognition," Frontiers in Psychology, vol. 2, articel 187, 2011.

[6] H. Chainay, L. Naouri, and A. Pavec, "Orientation priming of grasping decision for drawings of objects and blocks, and words," Memory and Cognition, vol. 39, no. 4, pp. 629-634, 2011.

[7] M. Tucker and R. Ellis, "Action priming by briefly presented objects," Acta Psychologica, vol. 116, no. 2, pp. 185-203, 2004.

[8] M. Tucker and R. Ellis, "The potentiation of grasp types during visual object categorization," Visual Cognition, vol. 8, no. 6, pp. 769-800, 2001.

[9] R. Ellis and M. Tucker, "Micro-affordance: the potentiation of components of action by seen objects," British Journal of Psychology, vol. 91, no. 4, pp. 451-471, 2000.

[10] J. Grèzes, M. Tucker, J. Armony, R. Ellis, and R. E. Passingham, "Objects automatically potentiate action: an fMRI study of implicit processing," European Journal of Neuroscience, vol. 17, no. 12, pp. 2735-2740, 2003.

[11] L. L. Chao and A. Martin, "Representation of manipulable manmade objects in the dorsal stream," NeuroImage, vol. 12, no. 4, pp. $478-484,2000$.

[12] J. Grèzes and J. Decety, "Does visual perception of object afford action? Evidence from a neuroimaging study," Neuropsychologia, vol. 40, no. 2, pp. 212-222, 2002.

[13] M. Tucker and R. Ellis, "On the relations between seen objects and components of potential actions," Journal of Experimental Psychology, vol. 24, no. 3, pp. 830-846, 1998.

[14] P. M. Fitts and R. L. Deininger, "S-R compatibility: correspondence among paired elements within stimulus and response codes," Journal of Experimental Psychology, vol. 48, no. 6, pp. 483-492, 1954.

[15] J. R. Simon and A. P. Rudell, "Auditory S-R compatibility: the effect of an irrelevant cue on information processing," Journal of Applied Psychology, vol. 51, no. 3, pp. 300-304, 1967.

[16] M. H. Fischer and C. D. Dahl, "The time course of visuo-motor affordances," Experimental Brain Research, vol. 176, no. 3, pp. 519-524, 2007.

[17] S. J. Anderson, N. Yamagishi, and V. Karavia, "Attentional processes link perception and action," Proceedings of the Royal Society B, vol. 269, no. 1497, pp. 1225-1232, 2002.

[18] E. Symes, R. Ellis, and M. Tucker, "Visual object affordances: object orientation," Acta Psychologica, vol. 124, no. 2, pp. 238$255,2007$.

[19] G. Buccino, M. Sato, L. Cattaneo, F. Rodà, and L. Riggio, "Broken affordances, broken objects: a TMS study," Neuropsychologia, vol. 47, no. 14, pp. 3074-3078, 2009.

[20] H. Ey, J. Ajuriaguerra, and H. Hecaen, "Troubles du schéma corporel et états de dépersonnalisation," in Les Rapports de la Neurologie et de la Psychiatrie, H. Et Cie, Ed., pp. 63-71, 1947.

[21] W. Mayer-Gross, “On depersonalization," British Journal of Medical Psychology, vol. 15, pp. 103-122, 1935.

[22] M. Heidegger, Sein und Zeit, Niemeyer, Halle, Germany, 1927.

[23] T. Fuchs and J. E. Schlimme, "Embodiment and psychopathology: a phenomenological perspective," Current Opinion in Psychiatry, vol. 22, pp. 570-575, 2009.

[24] G. Stanghellini, "Embodiment and schizophrenia," World Psychiatry, vol. 8, pp. 56-59, 2009.

[25] T. Fuchs, "Corporealized and disembodied minds: a phenomenological view of the body in melancholia and schizophrenia," Philosophy, Psychiatry and Psychology, vol. 12, pp. 95-107, 2005.

[26] W. Glannon, “Our brains are not us," Bioethics, vol. 23, pp. 321329, 2009.

[27] E. Matthews, Body-Subjects and Disordered Minds: Treating the "Whole" Personin Psychiatry, Oxford University Press, Oxford, UK, 2007.

[28] W. Blankenburg, "First steps toward a 'psychopathology of common sense", Philosophy, Psychiatry and Psychology, 8, pp. 303-315, 2001.

[29] L. A. Sass and J. Parnas, "Schizophrenia, consciousness and the self," Schizophrenia Bulletin, vol. 29, no. 3, pp. 427-444, 2003.

[30] L. A. Sass, "Schizophrenia, self-experience, and so-called 'negative symptoms," in Exploring the Self, D. Zahavi, Ed., pp. 149182, Benjamins, Amsterdam, The Netherlands, 2000.

[31] P. G. Enticott, K. E. Hoy, S. E. Herring, P. J. Johnston, Z. J. Daskalakis, and P. B. Fitzgerald, "Reduced motor facilitation during action observation in schizophrenia: a mirror neuron deficit?" Schizophrenia Research, vol. 102, no. 1-3, pp. 116-121, 2008.

[32] N. Franck, C. Farrer, N. Georgieff et al., "Defective recognition of one's own actions in patients with schizophrenia," The American Journal of Psychiatry, vol. 158, no. 3, pp. 454-459, 2001.

[33] C. Delerue and M. Boucart, "The relationship between visual exploration and action processing in schizophrenia," Cognitive Neuropsychiatry, vol. 17, pp. 334-350, 2012.

[34] S. Gastaldo, C. Umiltà, G. Bianchin, and M. Prior, "The Simon effect in schizophrenic patients with negative symptoms," Cortex, vol. 38, no. 2, pp. 149-159, 2002. 
[35] American Psychiatric Association, DSM-IV: Diagnostic and Statistical Manual of Mental Disorders, American Psychiatric Press, Washington, DC, USA, 4th edition, 1994.

[36] S. R. Kay, A. Fiszbein, and L. A. Opler, "The positive and negative syndrome scale (PANSS) for schizophrenia," Schizophrenia Bulletin, vol. 13, no. 2, pp. 261-276, 1987.

[37] R. C. Oldfield, "The assessment and analysis of handedness: the Edinburgh inventory," Neuropsychologia, vol. 9, no. 1, pp. 97-113, 1971.

[38] P. Zimmermann and B. Fimm, Testbatterie Zur Aufmerkamkeitsprüfung (TAP), Psytest, Würselem, Germany, 2005.

[39] M. I. Posner, T. S. Early, E. Reiman, P. J. Pardo, and M. Dhawan, "Asymmetries in hemispheric control of attention in schizophrenia," Archives of General Psychiatry, vol. 45, no. 9, pp. 814-821, 1988.

[40] S. D. Behrwind, M. Dafotakis, S. Halfter et al., "Executive control in chronic schizophrenia: a perspective from manual stimulus-response compatibility task performance," Behavioural Brain Research, vol. 223, no. 1, pp. 24-29, 2011.

[41] G. Stanghellini, "Schizophrenic consciousness, spiritual experience, and the borders between things, images and words," Transcultural Psychiatry, vol. 42, no. 4, pp. 610-629, 2005. 


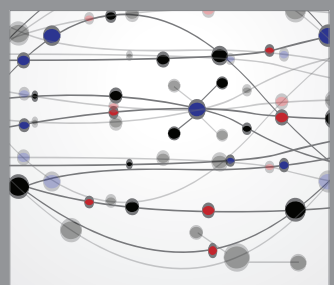

The Scientific World Journal
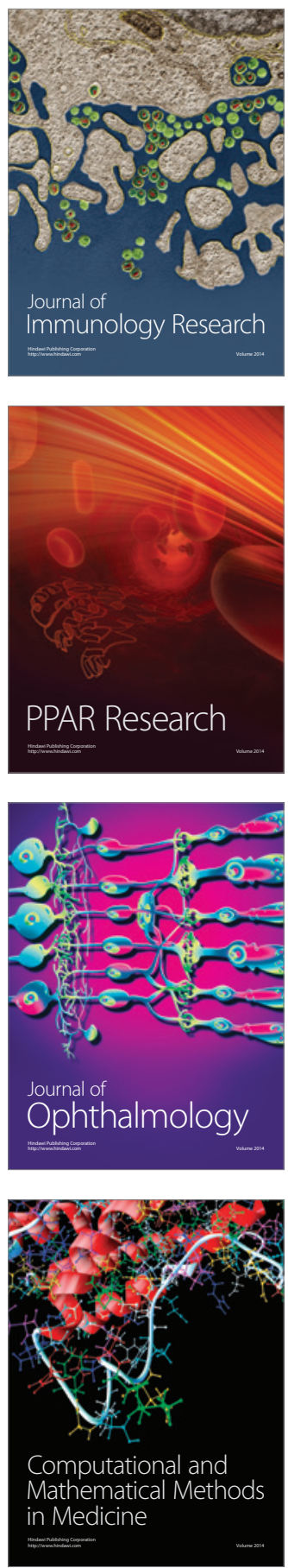

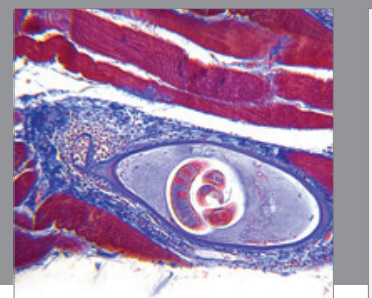

Gastroenterology

Research and Practice
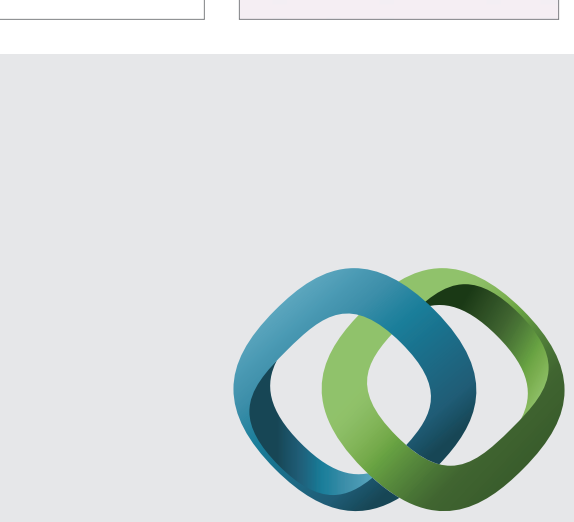

\section{Hindawi}

Submit your manuscripts at

http://www.hindawi.com
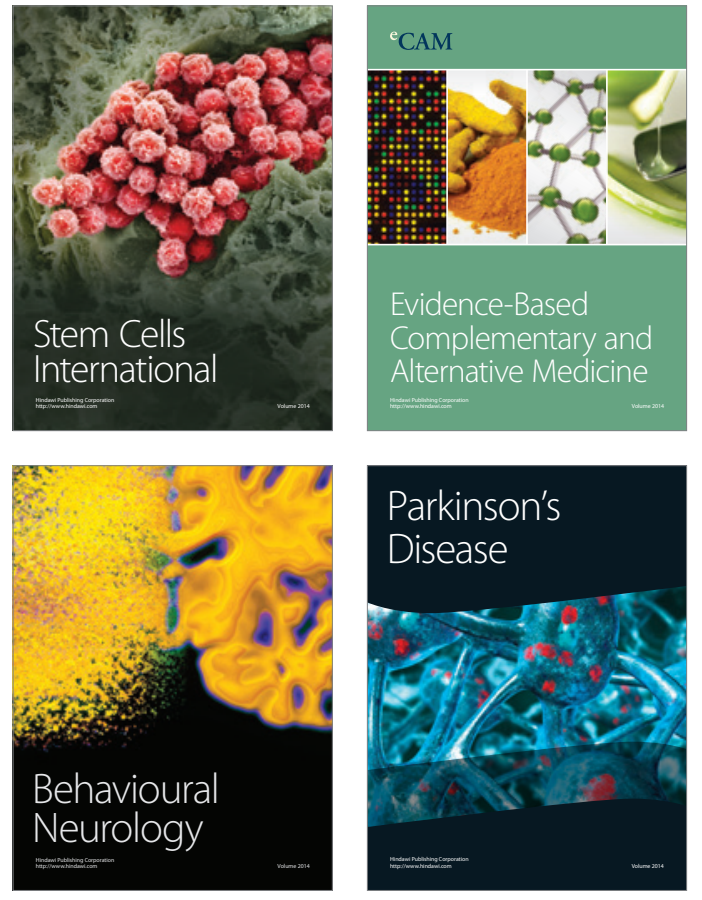
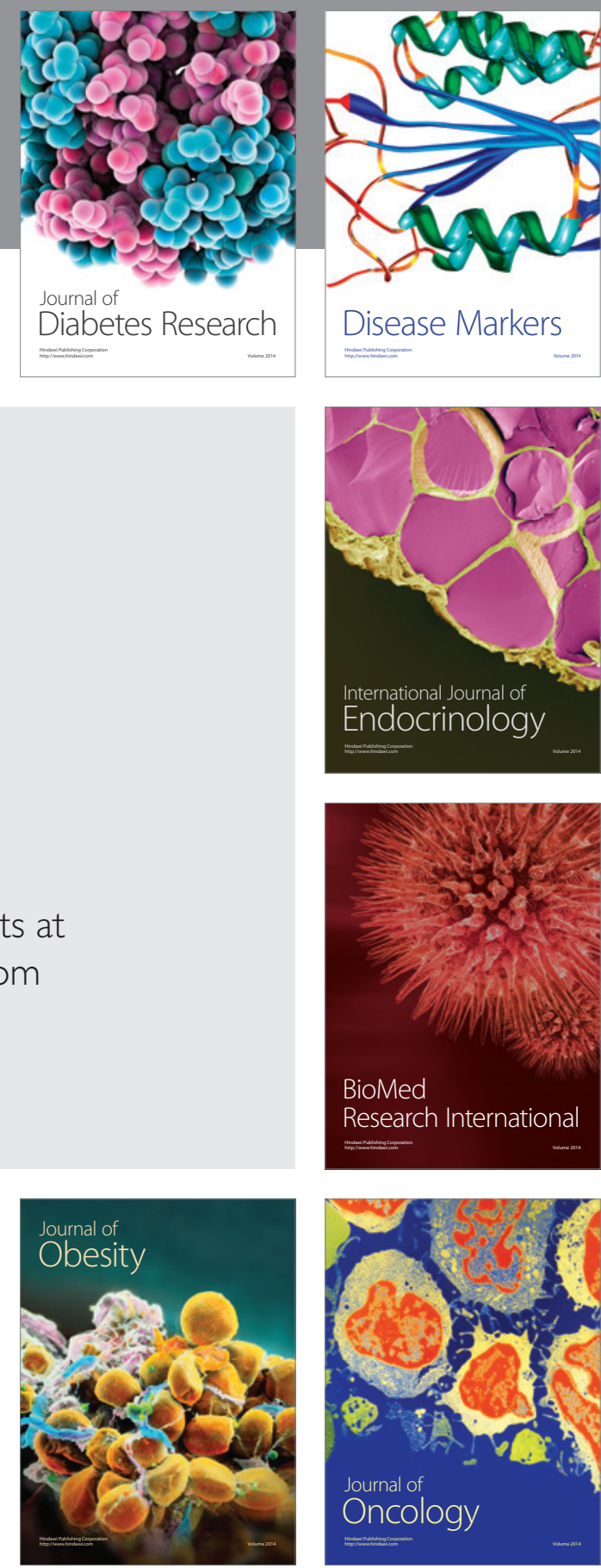

Disease Markers
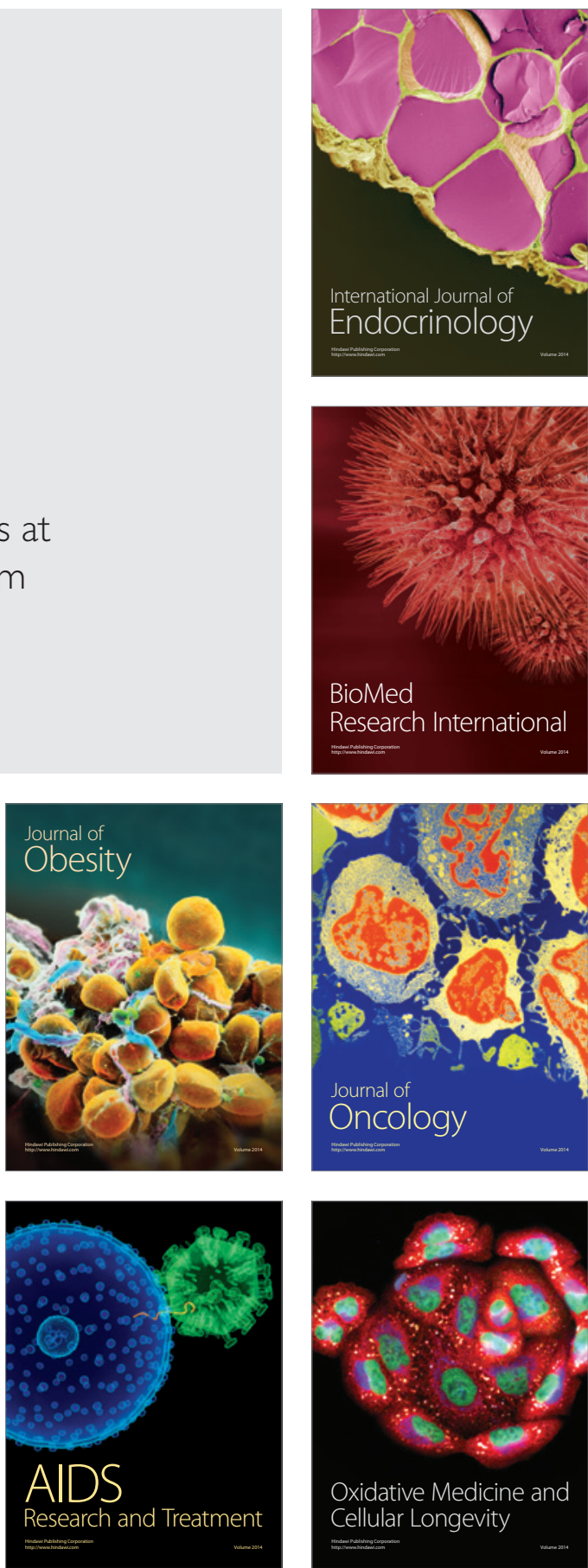